\title{
The primary cilium as a dual sensor of mechanochemical signals in chondrocytes
}

\author{
Hayat Muhammad • Yoach Rais • Nicolai Miosge • \\ Efrat Monsonego Ornan
}

Received: 24 August 2011/Revised: 18 December 2011/Accepted: 21 December 2011/Published online: 13 January 2012

(C) The Author(s) 2012. This article is published with open access at Springerlink.com

\begin{abstract}
The primary cilium is an immotile, solitary, and microtubule-based structure that projects from cell surfaces into the extracellular environment. The primary cilium functions as a dual sensor, as mechanosensors and chemosensors. The primary cilia coordinate several essential cell signaling pathways that are mainly involved in cell division and differentiation. A primary cilium malfunction can result in several human diseases. Mechanical loading is sense by mechanosensitive cells in nearly all tissues and organs. With this sensation, the mechanical signal is further transduced into biochemical signals involving pathways such as Akt, PKA, FAK, ERK, and MAPK. In this review, we focus on the fundamental functional and structural features of primary cilia in chondrocytes and chondrogenic cells.
\end{abstract}

Keywords Chondrocytes · Primary cilia .

Mechanotransduction - Chondorgenic progenitor cells

$\begin{array}{ll}\text { Abbreviations } \\ \text { OA } & \text { Osteoarthritis } \\ \text { ECM } & \text { Extracellular matrix } \\ \text { FAK } & \text { Focal adhesion kinase } \\ \text { MAPK } & \text { Mitogen-activated protein kinase }\end{array}$

H. Muhammad and Y. Rais contributed equally to this work.

H. Muhammad $\cdot$ N. Miosge $(\square)$

Tissue Regeneration Work Group, Department of

Prosthodontics, Georg August University, Robert-Koch-Str. 40,

37075 Goettingen, Germany

e-mail: nmiosge@gwdg.de

Y. Rais · E. M. Ornan

Faculty of Agricultural, Food and Environmental Sciences, Institute of Biochemistry and Nutrition, Hebrew University, POB 12, 76100 Rehovot, Israel

$\begin{array}{ll}\text { CPCs } & \text { Chondorgenic progenitor cells } \\ \text { ERK } & \text { Extracellular signal-regulated kinase } \\ \text { MSC } & \text { Mesenchymal stem cell } \\ \text { PKA } & \text { Protein kinase A } \\ \text { Hh } & \text { Hedgehog } \\ \text { IFT } & \text { Intraflagellar transport } \\ \text { Wnt } & \text { Wingless } \\ \text { EvC } & \text { Ellis-van Creveld syndrome } \\ \text { PKD } & \text { Polycystic kidney disease } \\ \text { Ihh } & \text { Indian Hedgehog }\end{array}$

\section{Introduction}

The morphological, structural, and material features of the cartilage are genetically programmed but can also be modified by epigenetic factors, such as local tissue stress and strain states [1, 2]. Mechanical stimulation resulting from weight loading, mobilization, and muscle contraction has an important role in bone formation and normal joint cavitation [3, 4]. Paralysis of the skeletal musculature is known to inhibit chondrogenesis in developing limbs [5], which thereby influences the length, mass, and mechanical properties of the forming bone [6-9]. The growth plate and articular cartilage are subjected to massive repeated mechanical forces, and they have a limited capacity for repair. Thus, understanding how articular cartilage is maintained and how mechanical loads are sensed by the chondrocytes is of primary importance.

\section{Sensing of mechanical signals}

Mechanosensitivity starts with external or internal mechanical responses, and the mechanical stimuli are transduced by 
the cell into a biochemical outcome. More precisely, this phenomenon is known as mechanochemical signaling or mechanotransduction. Multiple activation mechanisms are simultaneously at play, including the release of autocrine growth factors [10-17] activation of mechanically sensitive kinases, such as Src [18-22] focal adhesion kinase (FAK) [23-25] and extracellular-signal regulated kinase (ERK) [26-32] and initiation of second messenger signaling [33, 34]. Mechanical forces drive many cellular events, including proliferation, differentiation, and gene expression in adult differentiated cells and stem cells [35]. When trying to understand how cells can receive a variety of inputs and translate them into a response, we think of a system, or a cell organelle, that can perform these tasks. Interest in a specialized cell projection organ called the primary cilium has recently emerged. This organ was shown to have the ability to receive and transduce numerous cell signals [36]. Thus, the primary cilium is a good candidate to act as the cell's "control device" for mechanical stimulation because it projects as an "antenna" from the cell into the ECM, and it incorporates integrins, $\mathrm{G}$ protein receptors, and calcium channels into the cell membrane.

\section{Mechanosignaling in chondrocytes}

Ultrastructural studies have shown that each chondrocyte has such an immotile primary cilium. On chondrocytes, the primary cilia are oriented into the pericellular matrix environment of the chondron, and they interact with collagen types II and IV via receptors [37-42]. A physical and chemical deficiency in the chondroblastic and chondrocytic primary cilia results in skeletal and growth plate abnormalities due to improper ECM secretion [43-49]. Integrins, $\mathrm{G}$ proteins, and calcium channels on the primary cilium have all been implicated as mechanoreceptors [19, 50-53]. Numerous genes and pathways have been shown to be differentially regulated as a result of mechanical stimuli; for example, the phosphoinositide 3-kinase/Akt, protein kinase A (PKA) and Mitogen-activated protein kinase (MAPK) pathways [54-56]. It is reasonable to assume that mechanotransduction is a complex multi-component system that allows cells to integrate mechanical stimulations differing in intensity, frequency, duration, and orientation to generate appropriate biological responses, including cartilage formation and regeneration [57] and, especially, growth-plate formation [37, 58]. Mice and humans with mutations in ciliary genes often present with defects in skeletal development. Two human syndromes that include defects in endochondral bone formation were shown to be associated with mutations in ciliary genes. Asphyxiating thoracic dystrophy (Jeune's syndrome) is associated with a missense mutation in IFT80 (part of IFT complex B), and it presents with skeletal defects resembling those seen in sonic hedgehog homolog depletion. Furthermore, Ptc1 (hh receptor) expression is downregulated in the IFT80 mutant, suggesting that alterations in $\mathrm{Hh}$ signaling and Ellis-van Creveld syndrome $(\mathrm{EvC})$ are characterized by numerous skeletal and craniofacial abnormalities. The mutated protein in $\mathrm{EvC}$ has been localized to the base of the cilia expressed in chondrocytes and is required for normal $\mathrm{Hh}$ signaling. The disruption of $\mathrm{EvC}$ in mice resulted in a variety of skeletal abnormalities associated with diminished Ihh signaling [48].

Mice mutated in other ciliary genes also demonstrate alterations in endochondral ossification, resulting in a shortening of the long bones. Conditional deletion of IFT88 or KIF3a produces defects in embryonic endochondral bone formation, observed as early as 15.5 days from gestation [59]. These phenotypes resembled those seen in mice with germline mutations in Ihh [60]. When either Ift88 or KIF3a was deleted at later stages of development using the col2a-Cre promoter, the mice demonstrated a progressive loss of the cartilaginous growth plate, resulting in postnatal dwarfism that resembled the phenotype of mice with a conditional deletion of Ihh induced in postnatal cartilage. KIF3a and primary cilia are essential for coordination of chondrocytes maturation and condylar growth. The Ihh signaling pathway is one of the major regulatory pathways that lead to chondrocyte division and differentiation in the growth plate. Hydrostatic compression of the chondrocytic primary cilium upregulates Ihh gene expression [49, 61, 62].

Using electron microscopy, it has been shown that the chondrocyte cilium projects into the ECM and is tightly associated with the Golgi apparatus [39, 63]. Integrins have been shown to be present on the chondrocyte cilium, and integrin-dependent signaling cascades have been described in chondrocyte mechanotransduction [42, 64], suggesting a possible role for the chondrocytic cilia in mechanosensing. Chondrocytes in articular cartilage differ from those in the growth plate in that they are maintained as mature resting cells. Mechanical load is a critical factor in maintaining articular cartilage, but how the load is sensed is not known. Recently, the fate of the primary cilia on articular chondrocytes during the progression of bovine OA has been investigated $[47,65]$. Primary cilia were present during all examined stages of OA; however, the proportion of ciliated cells increased and their orientation towards the surface was altered; the significance of this orientation remains unclear [37, 63, 65]. Recently published cyclic compression experiments proved that mechanical loading modulates chondrocyte primary cilia incidence and length. This observation has been made independent from the well-known reduction of cilia appearance during cell division. Axonemal orientation in the cilia of articular 
chondrocytes is more pronounced in weight-bearing areas compared to of the cartilage tissue $[66,67]$.

We have studied the effect of loading on growth plate chondrocytes in vivo. Chondrocyte proliferation, differentiation, organization, and the major signaling pathways were found to be modified by loading in a chick model [68]. This demonstrated that the mechanical load affected chondrocytes in the growth plate [69], especially the expression of matrix metalloproteases [70].

\section{The primary cilium}

Primary cilia are non-motile sensory organelles that project from cells in many tissues and types of cells, such as kidney tubules, the bile duct, neurons, the endocrine pancreas, the thyroid, smooth muscle cells, and fibroblasts. The complete list of the cells and tissues containing primary cilia can be found at http://www.bowserlab.org/ primarycilia/cilialist.html. In recent years, cilia have emerged as a hot topic in research, resulting in the creation of numerous databases, including those containing genomic and proteomic data on cilium composition (http:// www.ciliaproteome.org, http://www.ciliome.com) [71-74]. Cilia can be seen as specialized cellular compartments or organelles [36, 75]. They are microtubule-based structures that originate at the basal body and extend into the extracellular space. The basal body is a modified form of the centriole, an organelle well known for its role as a microtubule organizing center of mitotic spindles. The basal body/centriole migrates toward the cell membrane and acts as a template for ciliogenesis and an anchor for the primary cilium. The centriole only moves towards the cell membrane when it is not involved in mitosis; thus, cilium generation occurs during the interphase of the cell. The intraflagellar transport (IFT) system plays a key role in primary cilium formation and maintenance. The IFT system is bidirectional and directs movement along the ciliary axoneme. Because no proteins are synthesized in the primary cilium itself, ciliary proteins are targeted to the basal body and transported to the distal tip through the IFT complex. IFT complexes are trafficked along the axoneme by molecular motor proteins; they are transported by kinesin II in the anterograde direction and by dynein II in the retrograde direction.

Motile and non-motile, primary cilia have microtubule axoneme cores made up of nine sets of microtubule doublets that provide structure and rigidity. However, primary cilia lack the central pair of microtubules (thus are designated $9+0$ ), while other motile machinery includes the inner and outer dynein arms, radial spokes, and central pair projections (designated 9+2). Unlike the motile cilia, of which there can be many per cell, there is only one primary cilium per cell [76-78].

\section{The function of the primary cilium}

To date, there are three hypotheses regarding the functional importance of the primary cilium: first, the primary cilium is a vestigial organ on the cell; second, that it inhibits cell division because it sequesters the centriole; and third, that it is a cellular sensory structure. The first hypothesis has been proven to be incorrect by several experiments. For instance, analyses of mutants, such as the $\operatorname{Tg} 737^{\text {orpk Rpw }}$ mouse, have indicated that a functioning primary cilium is essential for normal development and function, not only of the kidney, but also of many other tissues and organs. Hence, ciliary dysfunction might lead to a series of developmental abnormalities and diseases collectively called ciliopathies, including cystic diseases, obesity, and blindness, as well as behavioral, cognitive, and skeletal defects. The second hypothesis seems reasonable because the majority of cells possess primary cilia when they are not undergoing mitosis. Additionally, recent studies have demonstrated the accuracy of the third hypothesis: primary cilia have been shown to be highly involved in cell signaling processes because a number of ion channels, transporter proteins, and downstream effector proteins are associated with the cilium [79-81].

The primary cilium is a few micrometers in length, and it detects and interprets signals from the environment, such as odorants, fluid flow, and protein signaling between cells. Thus, they are spectacularly complex sensors. In ciliary signaling, the receptor protein and the protein that transmits the message into the cell are localized in the cilia. Protein association or dissociation from the cilia controls the signaling pathways, which ultimately trigger responses such as cell division and differentiation [82]. Several independent lines of evidence have demonstrated a role for the primary cilium in Hh signaling [83]. Hh is the master regulator of endochondral ossification in the growth plate, and it determines chondrocyte activity and subsequent bone length [84-86]. Upon Hh stimulation, both Hh receptors, Smo and ptch1, are recruited to the cilium in vitro and in vivo; Gli2 and Gli3, downstream effectors of $\mathrm{Hh}$, also localize to the cilium in the developing limbs $[45,87]$. Other pathways that have been shown to regulate chondrocyte activity but have not yet been linked to the cilium are as follows: bone morphogenic proteins, wingless (Wnts), fibroblast growth factors, and insulin-like growth factors, all of which are essential for normal cartilage formation. 
Fig. 1 a Electron micrograph of the primary cilium (Ax), the distal (Dc), and proximal (Pc) centriole. Bar $500 \mathrm{~nm}$. b Cross section of the proximal centriole. Bar $100 \mathrm{~nm}$. Reprinted from Jensen et al. (1979) with permission.

c Schematic presentation of the primary cilium with membrane signaling molecules that were described in it. d Human articular chondrocytes and f CPCs stained with acetylated $\alpha$-tubulin (tb, green) Abs to detect primary cilia (arrows), phalloidin (ph, red) and DAPI (DAPI, blue). e Tissue from the late stage of human OA exhibits surface fissures and cell clusters (the arrow indicates the tidemark). Breaks in the tidemark are filled with blood vessels, and the bone marrow is visible underneath the $\mathrm{OA}$ tissue. Reprinted from Koelling et al. [92] with permission from the publisher
A

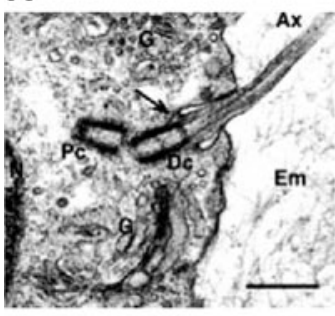

B

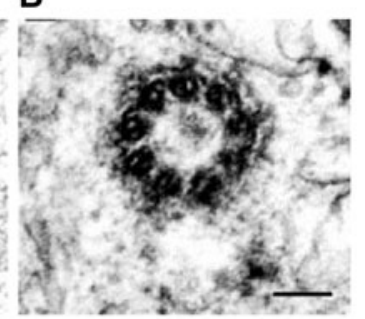

D

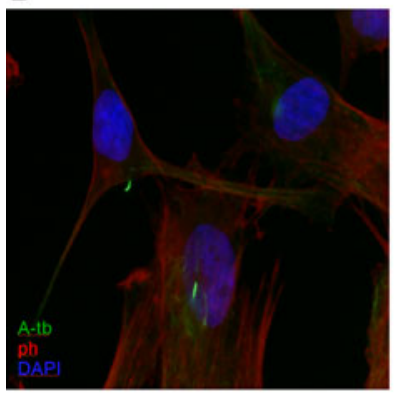

$\mathrm{F}$

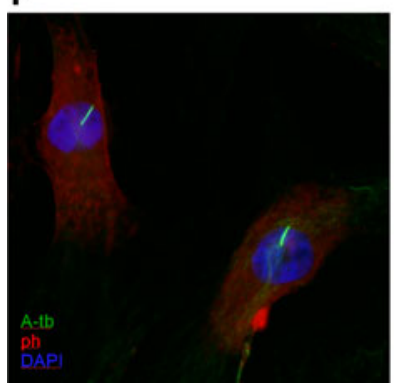

C

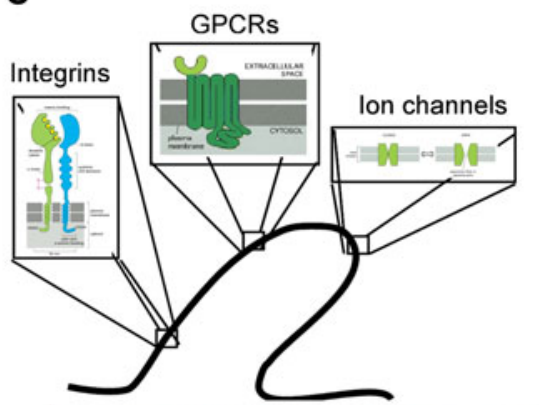

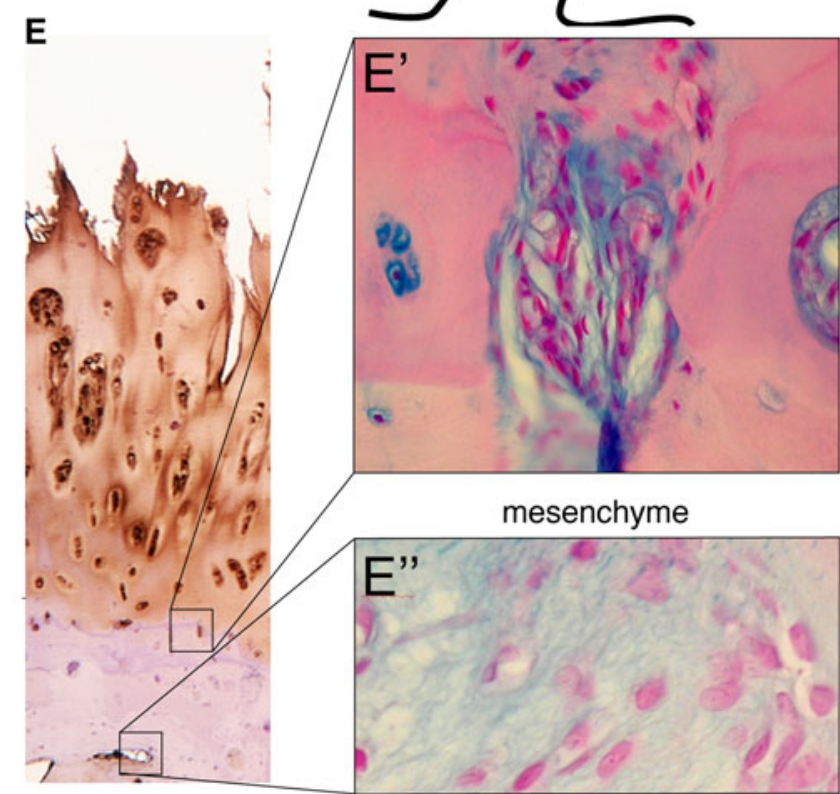

Cilia function in mesenchymal stem cells and chondrogenic progenitor cells (CPCs)

The effects of mechanical forces on mesenchymal stem cell (MSC) differentiation were examined in a fundamental study of the concept of environmental cell sensing. The study showed that differentiation of MSCs is directed by the stiffness of the culture matrix. On soft collagen gels that mimic the elasticity of brain tissue $(0.1-1 \mathrm{kPa})$, MSCs tend to adhere, spread, and exhibit a neurogenic phenotype. MSCs cultured on tenfold stiffer matrices that mimic muscle elasticity $(8-17 \mathrm{kPa})$ become spindle-shaped, similar to myoblasts. When cultured on matrices that mimic the stiffness of bone osteoid (25-40 kPa), the MSC phenotype becomes osteoblast-like with greater expression of osteogenic genes [88]. This work, along with similar studies, implies that a cell is able to sense its mechanical environment and that mechanical signaling itself can regulate the differentiation of MSCs into different tissues.

More recently, Padmaja Tummala et al. identified the presence of primary cilia on MSCs and determined their role in MSC differentiation. MSCs require primary cilia not only during their differentiation but also to maintain the

phenotypes of differentiated cells [89]. In addition, there is evidence that MSC differentiation into chondrocytes and osteocytes is regulated by mechanical signals [90]. Our research group is working on tissue regeneration to elucidate repair mechanisms, especially in OA (Fig. 1) and rheumatoid arthritis. OA is a chronic degenerative disease characterized by articular cartilage degeneration, and it is multifactorial in origin [89]. Primary cilia are present on chondrocytes, and the percentage of ciliated cells and the lengths of the cilia within OA tissue are higher compared to the normal tissue [65], although the implications of these facts have yet to be elucidated.

We have isolated CPCs from subjects in late-stage OA and characterized their role in the repair of diseased articular cartilage. CPCs have tremendous chondrogenic and regenerative potential. These cells are positive for stem cell markers and exhibit stem cell properties such as clonogenicity, multipotency, and migratory activity. Recently, we identified primary cilia projecting from the surfaces of CPCs using antibodies against acetylated alpha tubulin. Our laboratory is focused on using mechanobiological approaches to investigate the role of primary cilia in differentiation of CPCs into chondrocytes [91, 92]. 


\section{Conclusions and perspectives}

Owing to the involvement of primary cilia in fundamental cellular processes, mutations in primary ciliary proteins result in diverse diseases such as cystic kidney diseases, obesity, and retinal degeneration. Recent studies have presented a comprehensive concept that primary cilia are acting as dual sensors for physical and chemical cues. Therefore, over the past few years, many researchers have been paying attention to primary cilia to understand their role in development and diseases. Here, we have reviewed the basic role of primary cilia in mechanotransduction and their possible impact on cartilaginous tissues. Additionally, our results show that primary cilia project not only from the surface of human osteoarthritic chondrocytes but also from the surface of chondrogenic progenitor cells. One future line of research should be to elucidate the role of the primary cilia in chondrogenic differentiation to enhance the potential of cartilage repair.

Acknowledgments We would like to thank the American Journal Experts for editing the English language.

Open Access This article is distributed under the terms of the Creative Commons Attribution Noncommercial License which permits any noncommercial use, distribution, and reproduction in any medium, provided the original author(s) and source are credited.

\section{References}

1. Carter DR, Mikic B, Padian K (1998) Epigenetic mechanical factors in the evolution of long bone epiphyses. Zool J Linn Soc 123:163-178

2. Carter DR, Beaupré GS (2001) Skeletal function and form: mechanobiology of skeletal development, aging, and regeneration. Cambridge University Press, New York, p 332

3. Mikic B, Johnson TL, Chhabra AB, Schalet BJ, Wong M, Hunziker EB (2000) Differential effects of embryonic immobilization on the development of fibrocartilaginous skeletal elements. J Rehabil Res Dev 37:127-133

4. Osborne AC, Lamb KJ, Lewthwaite JC, Dowthwaite GP, Pitsillides AA (2002) Short-term rigid and flaccid paralyses diminish growth of embryonic chick limbs and abrogate joint cavity formation but differentially preserve pre-cavitated joints. J Musculoskelet Neuronal Interact 2:448-456

5. Murray PD, Drachman DB (1969) The role of movement in the development of joints and related structures: the head and neck in the chick embryo. J Embryol Exp Morphol 22:349-371

6. Hall BK, Herring SW (1990) Paralysis and growth of the musculoskeletal system in the embryonic chick. J Morphol 206:45-56

7. Hosseini A, Hogg DA (1991) The effects of paralysis on skeletal development in the chick embryo. I. General effects. J Anat 177:159-168

8. Hosseini A, Hogg DA (1991) The effects of paralysis on skeletal development in the chick embryo. II. Effects on histogenesis of the tibia. J Anat 177:169-178

9. Wong M, Germiller J, Bonadio J, Goldstein SA (1993) Neuromuscular atrophy alters collagen gene expression, pattern formation, and mechanical integrity of the chick embryo long bone. Prog Clin Biol Res 383B:587-597

10. Resnick N, Collins T, Atkinson W, Bonthron DT, Dewey C F Jr, Gimbron M A Jr (1993) Platelet-derived growth factor B chain promoter contains a cis-acting fluid shear-stress-responsive element. Proc Natl Acad Sci USA 90:7908

11. Liu M, Liu J, Buch S, Tanswell AK, Post M (1995) Antisense oligonucleotides for PDGF-B and its receptor inhibit mechanical strain-induced fetal lung cell growth. Am J Physiol 269:L178L184

12. Reusch P, Wagdy H, Reusch R, Wilson E, Ives HE (1996) Mechanical strain increases smooth muscle and decreases nonmuscle myosin expression in rat vascular smooth muscle cells. Circ Res 79:1046-1053

13. Robbins JR, Evanko SP, Vogel KG (1997) Mechanical loading and TGF-beta regulate proteoglycan synthesis in tendon. Arch Biochem Biophys 342:203-211

14. Cillo J E Jr, Gassner R, Koepsel RR, Buckley MJ (2000) Growth factor and cytokine gene expression in mechanically strained human osteoblast-like cells: implications for distraction osteogenesis. Oral Surg Oral Med Oral Pathol Oral Radiol Endod 90:147-154

15. Wu Q, Zhang Y, Chen Q (2001) Indian hedgehog is an essential component of mechanotransduction complex to stimulate chondrocyte proliferation. J Biol Chem 276:35290-35296

16. Zheng W, Seftor EA, Meininger CJ, Hendrix MJ, Tomanek RJ (2001) Mechanisms of coronary angiogenesis in response to stretch: role of VEGF and TGF-beta. Am J Physiol Heart Circ Physiol 280:H909-H917

17. Lindahl GE, Chambers RC, Papakrivopoulou J, Dawson SJ, Jacobsen MC, Bishop JE, Laurent GJ (2002) Activation of fibroblast procollagen alpha $1(\mathrm{I})$ transcription by mechanical strain is transforming growth factor-beta-dependent and involves increased binding of CCAAT-binding factor $(\mathrm{CBF} / \mathrm{NF}-\mathrm{Y})$ at the proximal promoter. J Biol Chem 277:6153-6161

18. Liu M, Qin Y, Liu J, Tanswell AK, Post M (1996) Mechanical strain induces pp60src activation and translocation to cytoskeleton in fetal rat lung cells. J Biol Chem 271:7066-7071

19. Han B, Bai XH, Lodyga M, Xu J, Yang BB, Keshavjee S, Post M, Liu M (2004) Conversion of mechanical force into biochemical signaling. J Biol Chem 279:54793-54801

20. Jiang G, Huang AH, Cai Y, Tanase M, Sheetz MP (2006) Rigidity sensing at the leading edge through alphavbeta3 integrins and RPTPalpha. Biophys J 90:1804-1809

21. Wang H, Riha GM, Yan S, Li M, Chai H, Yang H, Yao Q, Chen C (2005) Shear stress induces endothelial differentiation from a murine embryonic mesenchymal progenitor cell line. Arterioscler Thromb Vasc Biol 25:1817-1823

22. Na S, Collin O, Chowdhury F, Tay B, Ouyang M, Wang Y, Wang N (2008) Rapid signal transduction in living cells is a unique feature of mechanotransduction. Proc Natl Acad Sci USA 105:6626-6631

23. Li S, Kim M, Hu YL, Jalali S, Schlaepfer DD, Hunter T, Chien S, Shyy JY (1997) Fluid shear stress activation of focal adhesion kinase. Linking to mitogen-activated protein kinases. J Biol Chem 272:30455-30462

24. Smith PG, Garcia R, Kogerman L (1998) Mechanical strain increases protein tyrosine phosphorylation in airway smooth muscle cells. Exp Cell Res 239:353-360

25. Leucht P, Kim JB, Currey JA, Brunski J, Helms JA (2007) FAKmediated mechanotransduction in skeletal regeneration. PLoS One 2:e390

26. Yamazaki T, Komuro I, Kudoh S, Zou Y, Shiojima I, Mizuno T, Takano H, Hiroi Y, Ueki K, Tobe K (1995) Mechanical stress activates protein kinase cascade of phosphorylation in neonatal rat cardiac myocytes. J Clin Invest 96:438-446 
27. Takahashi M, Berk BC (1996) Mitogen-activated protein kinase (ERK1/2) activation by shear stress and adhesion in endothelial cells. Essential role for a herbimycin-sensitive kinase. J Clin Invest 98:2623-2631

28. Jalali S, Li YS, Sotoudeh M, Yuan S, Li S, Chien S, Shyy JY (1998) Shear stress activates p60src-Ras-MAPK signaling pathways in vascular endothelial cells. Arterioscler Thromb Vasc Biol 18:227-234

29. MacKenna DA, Dolfi F, Vuori K, Ruoslahti E (1998) Extracellular signal-regulated kinase and c-Jun NH2-terminal kinase activation by mechanical stretch is integrin-dependent and matrix-specific in rat cardiac fibroblasts. J Clin Invest 101:301-310

30. Schmidt C, Pommerenke H, Durr F, Nebe B, Rychly J (1998) Mechanical stressing of integrin receptors induces enhanced tyrosine phosphorylation of cytoskeletally anchored proteins. J Biol Chem 273:5081-5085

31. Chen NX, Ryder KD, Pavalko FM, Turner CH, Burr DB, Qiu J, Duncan RL (2000) $\mathrm{Ca}(2+)$ regulates fluid shear-induced cytoskeletal reorganization and gene expression in osteoblasts. Am J Physiol Cell Physiol 278:C989-C997

32. Iqbal J, Zaidi M (2005) Molecular regulation of mechanotransduction. Biochem Biophys Res Commun 328:751-755

33. Sadoshima J, Izumo S (1997) The cellular and molecular response of cardiac myocytes to mechanical stress. Annu Rev Physiol 59:551-571

34. Liu M, Tanswell AK, Post M (1999) Mechanical force-induced signal transduction in lung cells. Am J Physiol 277:L667-L683

35. Wang JH, Li B (2010) Mechanics rules cell biology. Sports Med Arthrosc Rehabil Ther Technol 2:16

36. Singla V, Reiter JF (2006) The primary cilium as the cell's antenna: signaling at a sensory organelle. Science 313:629-633

37. Wilsman NJ (1978) Cilia of adult canine articular chondrocytes. J Ultrastruct Res 64:270-281

38. Wilsman NJ, Farnum CE, Reed-Aksamit DK (1980) Incidence and morphology of equine and murine chondrocytic cilia. Anat Rec 197:355-361

39. Poole CA, Jensen CG, Snyder JA, Gray CG, Hermanutz VL, Wheatley DN (1997) Confocal analysis of primary cilia structure and colocalization with the Golgi apparatus in chondrocytes and aortic smooth muscle cells. Cell Biol Int 21:483-494

40. Poole CA, Zhang ZJ, Ross JM (2001) The differential distribution of acetylated and detyrosinated alpha-tubulin in the microtubular cytoskeleton and primary cilia of hyaline cartilage chondrocytes. J Anat 199:393-405

41. Jensen CG, Poole CA, McGlashan SR, Marko M, Issa ZI, Vujcich $\mathrm{KV}$, Bowser SS (2004) Ultrastructural, tomographic and confocal imaging of the chondrocyte primary cilium in situ. Cell Biol Int 28:101-110

42. McGlashan SR, Jensen CG, Poole CA (2006) Localization of extracellular matrix receptors on the chondrocyte primary cilium. J Histochem Cytochem 54:1005-1014

43. Zhang Q, Murcia NS, Chittenden LR, Richards WG, Michaud EJ, Woychik RP, Yoder BK (2003) Loss of the Tg737 protein results in skeletal patterning defects. Dev Dyn 227:78-90

44. Gouttenoire J, Valcourt U, Bougault C, Aubert-Foucher E, Arnaud E, Giraud L, Mallein-Gerin F (2007) Knockdown of the intraflagellar transport protein IFT46 stimulates selective gene expression in mouse chondrocytes and affects early development in zebrafish. J Biol Chem 282:30960-30973

45. Haycraft CJ, Zhang Q, Song B, Jackson WS, Detloff PJ, Serra R, Yoder BK (2007) Intraflagellar transport is essential for endochondral bone formation. Development 134:307-316

46. Koyama E, Young B, Nagayama M, Shibukawa Y, EnomotoIwamoto M, Iwamoto M, Maeda Y, Lanske B, Song B, Serra R, Pacifici M (2007) Conditional Kif3a ablation causes abnormal hedgehog signaling topography, growth plate dysfunction, and excessive bone and cartilage formation during mouse skeletogenesis. Development 134:2159-2169

47. McGlashan SR, Haycraft CJ, Jensen CG, Yoder BK, Poole CA (2007) Articular cartilage and growth plate defects are associated with chondrocyte cytoskeletal abnormalities in Tg737orpk mice lacking the primary cilia protein polaris. Matrix Biol 26:234-246

48. Ruiz-Perez VL, Blair HJ, Rodriguez-Andres ME, Blanco MJ, Wilson A, Liu YN, Miles C, Peters H, Goodship JA (2007) Evc is a positive mediator of Ihh-regulated bone growth that localises at the base of chondrocyte cilia. Development 134:2903-2912

49. Song JK, Niimi Y, Kupersmith MJ, Berenstein A (2007) Postnatal growth and development of a cerebral arteriovenous malformation on serial magnetic resonance imaging in a child with hemangiomatosis. Case report. J Neurosurg 106:384-387

50. Salter DM, Robb JE, Wright MO (1997) Electrophysiological responses of human bone cells to mechanical stimulation: evidence for specific integrin function in mechanotransduction. J Bone Miner Res 12:1133-1141

51. Hara F, Fukuda K, Asada S, Matsukawa M, Hamanishi C (2001) Cyclic tensile stretch inhibition of nitric oxide release from osteoblast-like cells is both $\mathrm{G}$ protein and actin-dependent. J Orthop Res 19:126-131

52. Hung CT, Allen FD, Pollack SR, Brighton CT (1996) Intracellular $\mathrm{Ca}^{2+}$ stores and extracellular $\mathrm{Ca}^{2+}$ are required in the realtime $\mathrm{Ca}^{2+}$ response of bone cells experiencing fluid flow. J Biomech 29:1411-1417

53. Malone AM, Anderson CT, Tummala P, Kwon RY, Johnston TR, Stearns T, Jacobs CR (2007) Primary cilia mediate mechanosensing in bone cells by a calcium-independent mechanism. Proc Natl Acad Sci USA 104:13325-13330

54. Danciu TE, Adam RM, Naruse K, Freeman MR, Hauschka PV (2003) Calcium regulates the PI3K-Akt pathway in stretched osteoblasts. FEBS Lett 536:193-197

55. Kanno T, Takahashi T, Tsujisawa T, Ariyoshi W, Nishihara T (2007) Mechanical stress-mediated Runx2 activation is dependent on Ras/ERK1/2 MAPK signaling in osteoblasts. J Cell Biochem 101:1266-1277

56. Wadhwa S, Choudhary S, Voznesensky M, Epstein M, Raisz L, Pilbeam C (2002) Fluid flow induces COX-2 expression in MC3T3-E1 osteoblasts via a PKA signaling pathway. Biochem Biophys Res Commun 297:46-51

57. Ott CE, Bauer S, Manke T, Ahrens S, Rodelsperger C, Grunhagen J, Kornak U, Duda G, Mundlos S, Robinson PN (2009) Promiscuous and depolarization-induced immediate-early response genes are induced by mechanical strain of osteoblasts. J Bone Miner Res 24:1247-1262

58. Serra R (2007) Intraflagellar transport in skeletal development. J Musculoskelet Neuronal Interact 7:302-303

59. Kolpakova-Hart E, Jinnin M, Hou B, Fukai N, Olsen BR (2007) Kinesin-2 controls development and patterning of the vertebrate skeleton by Hedgehog- and Gli3-dependent mechanisms. Dev Biol 309:273-284

60. St-Jacques B, Hammerschmidt M, McMahon AP (1999) Indian hedgehog signaling regulates proliferation and differentiation of chondrocytes and is essential for bone formation. Genes Dev 13:2072-2086

61. Kinumatsu T, Shibukawa Y, Yasuda T, Nagayama M, Yamada S, Serra R, Pacifici M, Koyama E (2011) TMJ development and growth require primary cilia function. J Dent Res 90(8):988-994

62. Shao YY, Wang L, Welter FJ, Ballock TR (2011) Primary cilia modulate Ihh signal transduction in response to hydrostatic loading of growth plate chondrocytes. Bone 50:79-84

63. Poole CA, Flint MH, Beaumont BW (1985) Analysis of the morphology and function of primary cilia in connective tissues: a cellular cybernetic probe? Cell Motil 5:175-193 
64. Praetorius HA, Praetorius J, Nielsen S, Frokiaer J, Spring KR (2004) Beta1-integrins in the primary cilium of MDCK cells potentiate fibronectin-induced $\mathrm{Ca}^{2+}$ signaling. Am J Physiol Renal Physiol 287:F969-F978

65. McGlashan SR, Cluett EC, Jensen CG, Poole CA (2008) Primary cilia in osteoarthritic chondrocytes: from chondrons to clusters. Dev Dyn 237:2013-2020

66. McGlashan SR, Knight MM, Chowdhury TT, Joshi P, Jensen GG, Kennedy S, Poole AC (2010) Mechanical loading modulates chondrocyte primary cilia incidence and length. Cell Biol Int 34:441-446

67. Farnum CE, Wilsman NJ (2011) Orientation of primary cilia of articular chondrocytes in three dimensional space. Anat Rec (Hoboken) 294(3):533-549

68. Reich A, Jaffe N, Tong A, Lavelin I, Genina O, Pines M, Sklan D, Nussinovitch A, Monsonego-Ornan E (2005) Weight loading young chicks inhibits bone elongation and promotes growth plate ossification and vascularization. J Appl Physiol 98:2381-2389

69. Reich A, Sharir A, Zelzer E, Hacker L, Monsonego-Ornan E, Shahar R (2008) The effect of weight loading and subsequent release from loading on the postnatal skeleton. Bone 43:766-774

70. Reich A, Maziel SS, Ashkenazi Z, Ornan EM (2010) Involvement of matrix metalloproteinases in the growth plate response to physiological mechanical load. J Appl Physiol 108:172-180

71. Verghese E, Zhuang J, Saiti D, Ricardo SD, Deane JA (2011) In vitro investigation of renal epithelial injury suggests that primary cilium length is regulated by hypoxia-inducible mechanisms. Cell Biol Int 35:909-913

72. Inglis PN, Boroevich KA, Leroux MR (2006) Piecing together a ciliome. Trends Genet 22:491-500

73. Gherman A, Davis EE, Katsanis N (2006) The ciliary proteome database: an integrated community resource for the genetic and functional dissection of cilia. Nat Genet 38:961-962

74. Ostrowski LE, Blackburn K, Radde KM, Moyer MB, Schlatzer DM, Moseley A, Boucher RC (2002) A proteomic analysis of human cilia: identification of novel components. Mol Cell Proteomics 1:451-465

75. Rosenbaum JL, Witman GB (2002) Intraflagellar transport. Natl Rev Mol Cell Biol 3:813-825

76. Pedersen LB, Rosenbaum JL (2008) Intraflagellar transport (IFT) role in ciliary assembly, resorption and signalling. Curr Top Dev Biol 85:23-61

77. Praetorius HA, Spring KR (2005) A physiological view of the primary cilium. Annu Rev Physiol 67:515-529

78. Temiyasathit S, Jacobs CR (2010) Osteocyte primary cilium and its role in bone mechanotransduction. Ann N Y Acad Sci 1192:422-428
79. Lehman JM, Michaud EJ, Schoeb TR, Aydin-Son Y, Miller M, Yoder BK (2008) The Oak Ridge polycystic kidney mouse: modeling ciliopathies of mice and men. Dev Dyn 237:1960-1971

80. Quinlan RJ, Tobin JL, Beales PL (2008) Modeling ciliopathies: primary cilia in development and disease. Curr Top Dev Biol 84:249-310

81. Veland IR, Awan A, Pedersen LB, Yoder BK, Christensen ST (2009) Primary cilia and signaling pathways in mammalian development, health and disease. Nephron Physiol 111:p39-p53

82. Badano JL, Mitsuma N, Beales PL, Katsanis N (2006) The ciliopathies: an emerging class of human genetic disorders. Annu Rev Genomics Hum Genet 7:125-148

83. Huangfu D, Anderson KV (2006) Signaling from Smo to Ci/Gli: conservation and divergence of Hedgehog pathways from Drosophila to vertebrates. Development 133:3-14

84. Alvarez J, Sohn P, Zeng X, Doetschman T, Robbins DJ, Serra R (2002) TGFbeta2 mediates the effects of hedgehog on hypertrophic differentiation and PTHrP expression. Development 129:1913-1924

85. Kobayashi T, Soegiarto DW, Yang Y, Lanske B, Schipani E, McMahon AP, Kronenberg HM (2005) Indian hedgehog stimulates periarticular chondrocyte differentiation to regulate growth plate length independently of PTHrP. J Clin Invest 115:1734-1742

86. Kronenberg HM (2006) PTHrP and skeletal development. Ann N Y Acad Sci 1068:1-13

87. Rohatgi R, Milenkovic L, Scott MP (2007) Patched1 regulates hedgehog signaling at the primary cilium. Science 317:372-376

88. Engler AJ, Sen S, Sweeney HL, Discher DE (2006) Matrix elasticity directs stem cell lineage specification. Cell 126:677-689

89. Tummala P, Arnsdorf EJ, Jacobs CR (2010) The role of primary cilia in mesenchymal stem cell differentiation: a pivotal switch in guiding lineage commitment. Cell Mol Bioeng 3:207-212

90. Kelly DJ, Jacobs CR (2010) The role of mechanical signals in regulating chondrogenesis and osteogenesis of mesenchymal stem cells. Birth Defects Res C Embryo Today 90:75-85

91. Koelling S, Miosge N (2010) Sex differences of chondrogenic progenitor cells in late stages of osteoarthritis. Arthritis Rheum 62:1077-1087

92. Koelling S, Kruegel J, Irmer M, Path JR, Sadowski B, Miro X, Miosge N (2009) Migratory chondrogenic progenitor cells from repair tissue during the later stages of human osteoarthritis. Cell Stem Cell 4:324-335 